\title{
Associations of overweight and metabolic health with successful aging : 32-year follow-up of the Helsinki Businessmen Study
}

\section{Jyväkorpi, Satu K.}

2020-05

Jyväkorpi , S K , Urtamo , A , Strandberg , A Y , von Bonsdorff , M , Salomaa , V , Kivimäki , M , Luotola , K \& Strandberg , T E 2020 , ' Associations of overweight and metabolic health with successful aging : 32-year follow-up of the Helsinki Businessmen Study ' , Clinical Nutrition , vol. 39 , no. 5 , pp. 1491-1496 . https://doi.org/10.1016/j.clnu.2019.06.011

http://hdl.handle.net/10138/329506

https://doi.org/10.1016/j.clnu.2019.06.011

cc_by_nc_nd

acceptedVersion

Downloaded from Helda, University of Helsinki institutional repository.

This is an electronic reprint of the original article.

This reprint may differ from the original in pagination and typographic detail.

Please cite the original version. 


\section{Associations of Overweight and Metabolic Health with 2 Successful Aging: 32-Year Follow-up of the Helsinki 3 Businessmen Study}

4 Brief title. Overweight and successful aging

5

6

7 8

Satu K Jyväkorpi ${ }^{1}$, PhD, Annele Urtamo ${ }^{1}$, MSc, Arto Y. Strandberg ${ }^{1}$, MD, PhD, Mikaela von Bonsdorff ${ }^{2,3}, \mathrm{PhD}$, Veikko Salomaa ${ }^{4}, \mathrm{PhD}$, Mika Kivimäki ${ }^{1,5}$, PhD, FMedSci, Kari Luotola $^{1} \mathrm{MD}, \mathrm{PhD}$, Timo E. Strandberg ${ }^{1,6}, \mathrm{MD}, \mathrm{PhD}$

${ }^{1}$ University of Helsinki, Clinicum, and Helsinki University Hospital, Helsinki, Finland

${ }^{2}$ Folkhälsan Research Centre, Helsinki, Finland

${ }^{3}$ University of Jyväskylä, Faculty of Sport and Health Sciences, Jyväskylä, Finland

${ }^{4}$ THL-National Insitute for Health and Welfare, Helsinki, Finland

${ }^{5}$ Department of Epidemiology and Public Health, University College London, London, UK

${ }^{6}$ University of Oulu, Center for Life Course Health Research, Oulu, Finland

*Address correspondence to Satu Jyväkorpi, PhD University of Helsinki, Tukholmankatu 8, PO Helsinki, Finland;

email:satu.jyvakorpi@gery.fi; tel: +358 504920970

Word count: 2618 


\section{Abstract}

Background \& Aims: Prognostic significance of metabolically healthy overweight and obesity (MHO) is under debate. However the relationship between MHO and health-related quality of life (HRQoL) is less studied. We compared successful aging (longevity plus HRQoL) in men with MHO, metabolically healthy normal weight (MHN) and metabolically unhealthy overweight and obesity (MUO).

Methods: In the Helsinki Businessmen Study longitudinal cohort, consisting of men born 1919 to 1934 . In 1985/86, overweight (BMI $\geq 25 \mathrm{~kg} / \mathrm{m}^{2}$ ) and metabolic health were determined in 1309 men (median age 60 years). HRQoL was assessed using RAND-36/SF-36 in 2000 and 2007, and all-cause mortality retrieved from registers up to 2018. The proportion of men reaching 90 years was also calculated.

Results: Of the men, 469 (35.8\%), 538 (41.1\%), $276(21.1 \%)$, and $26(2.0 \%)$ were MHN, MHO, MUO and MUN, respectively. During the 32-year follow-up, 72.3\% men died. With MHN as reference, adjusted hazard ratio with all-cause mortality was 1.08 (95\% confidence interval [CI] 0.93 to 1.27 ) for MHO, and 1.18 (95\% CI 0.95 to 1.47) for MUO. During follow-up, 273 men reached 90 years. With MHN as reference, adjusted odds ratio for MHO was $0.82(95 \%$ CI 0.59 to 1.14$)$ and 0.62 (95\% CI 0.41 to 0.95$)$ for MUO. Men in MHN group scored generally highest in RAND-36 HRQoL subscales in 2000 and 2007, of those significantly better in Physical functioning, Role physical, Role emotional, Bodily Pain, and General health sub-scales compared to MHO group in 2000.

Conclusions: As compared to MHN, MHO in late midlife does not increase mortality, but impairs odds for successful aging.

KEY WORDS. Quality of life, RAND-36, nonagenarians, successful aging, metabolically healthy overweight and obesity, metabolically unhealthy overweight and obesity 


\section{Highlights}

52

60

61

62

63

64

65

66

67

- Metabolically unhealthy obesity (MHO) in late midlife did not increase mortality in this study.

- MHO impaired odds for successful aging defined as longevity and Health Related Quality of Life.

- Participants with metabolically healthy normal weight (MHN) at baseline had better HRQoL quality of life at old age compared to those with MHO or Metabolically unhealthy overweight (MUO) at baseline.

- Men with MHN had higher odds of reaching 90 years than those men with MHO or MUO at baseline.

\section{(1)} 62

ABBREVIATIONS. BMI=body mass index; $\mathrm{CVD}=$ cardiovascular disease; $\mathrm{HRQ}$ oL=healthrelated quality of life; MetS=metabolic syndrome; $\mathrm{MHN}=$ metabolically healthy normal weight; $\mathrm{MHO}=$ metabolically healthy overweight and obesity; $\mathrm{MUN}=$ metabolically unhealthy normal weight; $\mathrm{MUO}=$ metabolically unhealthy overweight and obesity; 


\section{Introduction}

Overweight and obesity are prevalent worldwide, and promote morbidity and mortality, especially from cardiovascular disease (CVD) (1). This is thought to be due to the associations of overweight and obesity with various CVD risk factors, including hypertension, dyslipidemia, hyperglycemia, and metabolic syndrome. However, not all overweight people have these risk factors and present therefore the phenotype of a metabolically healthy overweight (MHO) (2). Its prevalence varies considerably depending on the criteria used (3.3$32.1 \%$ in men), but it has been suggested that $9 \%$ to $16 \%$ of obese individuals are metabolically healthy $(3,4)$. Despite being a relatively common condition and after wide research activity, the clinical significance of MHO is still under debate $(2,5)$. It seems to be closely related to physical activity and cardiorespiratory fitness, and if these are taken into account, the prognosis of MHO may not be worse than that of individuals with metabolically healthy normal weight (MHN), at least according to short-term studies $(6,7)$. As age increases, MHO may turn into metabolically unhealthy overweight (MUO) (8), but to our knowledge there are no studies on whether MHO affects the probability of reaching very old age, over 90 years.

Moreover, longevity may not be desirable if quality of life is not maintained and the prolonged life span is not healthy. Weight gain up to midlife has been shown to sensitively affect health-related quality of life (HRQoL) in old age (more weight gain, worse HRQoL), but whether this applies to MHO is not known (9). Although there is no consensus regarding the definition of successful aging (10), longevity with preserved quality of life could define the concept in a simple way. The objective of the present analysis was to compare various combinations of body mass index (BMI) and metabolic health with HRQoL in a prospective long-term study, where a substantial proportion of participants reached 90 years of age. 


\section{Methods}

93

94

\section{Study population}

Helsinki Businessmen Study (HBS) is a cohort of Finnish men, born 1919 to 1934, who have been followed-up since the 1960s in several waves and various constellations $(11,12)$. This male cohort is socioeconomically and ethnically homogenous and consequently some important confounders are intrinsically avoided. The follow-up study has been approved by the ethical committee of the Department of Medicine, Helsinki University Central Hospital and the study is registered with ClinicalTrials.gov identifier: NCT02526082.

In HBS, participants' CVD risk factor history is known since midlife (13). In the present analysis we focused on a representative sample of men in this cohort who were clinically healthy in 1974 and who responded to a health survey and underwent laboratory examinations in $1985 / 86$, when their median age was 60 years $(n=1399)$. Although part of the cohort participated in a prevention trial during the 1970s (14), that did not affect the results of the present long-term analyses and all men were included. The flow chart of the study is shown in figure 1.

\section{Metabolic status}

At baseline examination, serum lipids, fasting blood glucose levels, blood pressure and waist circumference were measured as described earlier, and questionnaires were used to define health, lifestyle, and background characteristics (15). Using data from these examinations, we determined the presence of metabolic syndrome (MetS) according to the International Diabetes Federation definition (Table 1) in 1309 participants (93.4\%) (16).We used the definition used in the MESA (16) in order to ease comparisons with American studies. 
However, using a definition with waist circumference $\geq 94 \mathrm{~cm}$ plus at least 2 other factors of

115 MetS did not change the general conclusions in the present study.

116

117

In the 1309 participants, the prevalence of normal weigh (BMI $<25 \mathrm{~kg} / \mathrm{m}^{2}$ ), overweight (BMI $\left.25-29 \mathrm{~kg} / \mathrm{m}^{2}\right)$, and obesity $\left(\mathrm{BMI} \geq 30 \mathrm{~kg} / \mathrm{m}^{2}\right)$ were $38.3 \%(\mathrm{n}=501), 52.3 \%(\mathrm{n}=684)$, and $9.5 \%$ $(n=124)$, respectively. Because of the relatively low number of obese men in this older cohort, we defined the metabolic status groups according to normal weight vs overweight plus obesity (Table 2). Metabolically Healthy Normal weight (MHN), Metabolically Unhealthy Normal weight (MUN), Metabolically Healthy Overweight (MHO) and Metabolically Unhealthy Overweight (MUO) phenotype groups comprised 469 (35.8\%), 26 (2.0\%), 538 (41.1\%), and $276(21.1 \%)$ men, respectively.

Because laboratory indicators of metabolic health were not available in 2000 or 2007, we used both information on prescribed medication for hypertension and diabetes up to 2007, and self-reported data of these conditions in the questionnaires. Both diabetes and antihypertensive medication are reimbursed by the Finnish Social Security Office, which keeps statistics of prescribed medications in Finland. We used the personal identification number (unique for all Finnish residents) to retrieve information for our cohort from the Social Security Office registers. Reimbursement requires the fulfilment of strict diagnostic criteria, but because cheap medications may be used without reimbursement, we considered it important to combine register data with self-report of hypertension and diabetes.

At baseline and in 2000 and 2007, physical activity was assessed with the questions: "Do you exercise regularly weekly, yes/no" and if yes "How many hours weekly?" In 2000, men were also asked how many hours they exercised heavily causing breathlessness/sweating. 


\section{Health related quality of life}

The RAND-36 HRQoL instrument (practically identical to Short Form [SF]-36) was used to assess HRQoL (17), and it has been validated in Finnish population (18). RAND-36 consists of 8 subscales: Physical function, Role limitations caused by physical health problems, Role limitations caused by emotional problems, Vitality, Mental health, Social functioning, Bodily pain, and General health (17). In the HBS cohort, HRQoL using RAND-36 has been assessed regularly since 2000; for the present analyses we used data of from mailed questionnaire waves in 2000 (mean age of respondents 73 years), and 2007 (mean age 80 years). We calculated the 8 subscales using standard procedures and used them separately in the analyses $(17,18)$.

\section{All-cause mortality}

The number of survivors in the cohort was updated through March 15, 2018 from the Population Information System of Finland, and total mortality and proportion of men reaching 90 years was calculated.

\section{Statistical analysis}

Descriptive statistics, Armitage test for trend in proportions, and analysis of covariance (ANCOVA, Bonferroni test for multiple comparisons) were used to compare the metabolic status groups. Because men with MUN at baseline only included 26 men we excluded them from HRQoL and mortality analyses. Because men with MetS as defined ( $\geq 3$ components out of 5) may still have factors affecting HRQoL, the ANCOVA analyses of HRQoL in 2000 and 2007 were conservatively adjusted for age, baseline systolic blood pressure, triglycerides, and smoking. Also the association of weekly exercise at baseline or during follow-up was tested. As sensitivity analyses we assessed the association of baseline overweight without all MetS components (except waist circumference) with HRQoL in 2000. Cumulative mortality up to 
March 15, 2018 in MHN, MHO, and MUO groups were compared using Kaplan-Meier curves and log-rank testing. Mortality in the groups was further compared using Cox's regression analysis (after ensuring the proportional hazards assumption), and hazard ratios (HR) with 95\% confidence intervals (CI) were calculated. Logistic regression was used to compare metabolic groups in reaching 90 years of age. Statistical analyses were performed using NCSS statistical software (Kaysville, UT, www.ncss.com, version 8).

\section{Results}

Of the participating men, 37\%, 41\%, 20\% and 2\% were MHN, MHO, MUO and MUN, respectively in 2000 .

The prevalence of hypertension and diabetes (self-report and drug reimbursement data combined) up to 2007 was used to reflect metabolic health during follow-up. Baseline characteristics, and BMI, smoking, exercise, and alcohol consumption during follow-up in all metabolic groups are shown in Table 2. The differences in BMI between metabolic status groups remained during the 21-year follow-up, but there was a significant decrease of BMI inside the groups among those who survived to 2007. In MHN, BMIs were 23.4 (SE 0.1), $23.5(0.1)$, and $23.1(0.1)$ in 1985/86, 2000, and 2007, respectively ( $\mathrm{P}=0.01)$. In MHO, 26.9 (0.1), $26.9(0.1)$, and $26.2(0.1)$, respectively (P<0.001). In MUO, $29.0(0.3), 28.3(0.3)$, and 27.3 (0.3), respectively ( $\mathrm{P}<0.001)$. In MUN, $24.1(0.3), 23.9(0.3)$, and $22.9(0.3)$, respectively $(\mathrm{P}=0.12)$

At baseline, compared to MHN group, MHO group tended to have higher blood pressure, serum triglycerides and lower HDL-cholesterol, whereas blood glucose and LDL-cholesterol were comparable. Alcohol consumption was higher and history of smoking more prevalent among the MHO group as compared to the men with MHN. In MUO, all risk factors and 
lifestyle variables were less favorable as compared to those associated with MHN and MHO.

The proportion of men reporting no exercise decreased in the order MHN, MHO and MUO, whereas weekly time of exercise among active men was similar between the groups.

Except for BMI, the characteristics in MUN largely compared to those in MUO, but because of few men included, MUN was excluded from further analyses.

Hypertension was present in $46.1 \%, 46.2 \%$, and $68.6 \%$ of the MHN, MHO, and MUO men, respectively ( $\mathrm{p}<0.001$ between groups); diabetes in $6.4 \%, 8.7 \%$ and $28.3 \%$ of the MHN, MHO, and MUO men, respectively ( $\mathrm{p}<0.001$ between groups). While both conditions (hypertension, diabetes) were less prevalent according to drug reimbursement, the differences between the metabolic groups were similar (data not shown).

The HRQoL data in the metabolic groups in 2000 and 2007 are shown in Table 3. To control for baseline factors potentially affecting HRQoL, the RAND-36 subscales were adjusted for age, baseline systolic blood pressure, log triglycerides, and smoking. Overall, the average scores of all subscales, especially physical ones, were highest in MHN, whereas the scores were more comparable between MHO and MUO. We also tested adjustment for physical activity at baseline or during follow-up, but it did not materially change the results.

During the 32-year follow-up, 947 (72.3\%) men died; cumulative mortality curves are shown in Figure 2. MUO had highest crude mortality (79.7\%), while mortality was quite similar between MHO (70.6\%), and MHN (69.2\%). The proportions of men reaching 90 years were $15.6 \%, 19.1 \%$, and $25.6 \%$ in MUO, MHO, and MHN, respectively. Adjusted risks for mortality and odds of reaching 90 years are shown in Table 4. While long-term mortality risk in MUO was significantly higher than in MHN or MHO when adjusted for age alone, differences disappeared when further adjusted for baseline smoking, systolic blood pressure 
and log triglycerides. In contrast, MUO men had, and MHO tended to have lower odds of reaching 90 years of age after full adjustments.

\section{Discussion}

While adjusted cumulative 32-year all-cause mortality was similar among men with MHO and MHN, MHO was associated with lesser odds of reaching 90 years of age than MHN. Also, physical components of quality of life were consistently worse at 73 years and 80 years among men with $\mathrm{MHO}$ at the baseline as compared to MHN. These results suggest that at least in men, who have survived to late midlife, MHO is not a "healthy" condition in older age and reduces odds for successful aging. In general, our results highlight and suggest an important difference: survival prognosis is driven by metabolic health, but odds for successful aging are driven by overweight/obesity in midlife. In other words, longer life may nevertheless be of poorer quality.

The overall evidence concerning the association between metabolically healthy overweight/obesity and CVD has been described as "broad and mixed" (16), Our results support those who have been critical of the concept (4) by demonstrating that even already metabolically healthy overweight, not only obesity, is related to less successful aging. One of the explanations for conserved metabolic health despite obesity has been more physical activity and good cardiorespiratory fitness which counteract metabolic disturbances $(6,19)$. There were more men without regular reported exercise in the MHO group as compared to the MHN group, but differences were not large, mortality was similar, and HRQoL differences remained after adjustment for physical activity. On the other hand, MHO may also turn into MUO when people age (5). A recent study showed that MHO is not a stable state and during the 12.2-year follow-up, half of those with MHO phenotype progressed to MetS and increased 
their risk of CVD events $(5,18))$. Similarly, a recent study from the Nurses' Health study reported that even when metabolic health is maintained during long periods of time, obesity remains a risk factor for CVD (20). In a recent study individuals with MHO had a higher risk of coronary heart disease, cerebrovascular disease, and heart failure as those with MHN (21). In our cohort MHO was associated with slightly more diabetes, but not hypertension, than men with MHN during follow-up. In contrast, men with MUO at baseline developed clearly more diabetes and hypertension up to 2007.

In aging societies, successful and functional aging is an increasingly important goal, but so far data on long-term predictors of successful aging have been relatively scarce. A recent longitudinal study of the Whitehall cohort reported findings similar to our study: Those who had MHO at baseline had a 2- fold higher decline in physical functioning over the course of 20 years, and a 6-fold higher worsening of bodily pain compared to MHN individuals (22). Similarly, although not categorized according to metabolic health, excess BMI was associated with substantially shorter healthy and chronic disease-free life expectancy between ages 50 to 75 years, consequently linking normal BMI to successful aging (23).

\section{Strengths and limitations}

The strengths of our study include the extended follow-up, excellent to good participation even in the last survey in 2007 , and reliable retrieval of data from national registers. Furthermore, we used the widely accepted definition of metabolic status by the International Diabetes Federation definition (16), which makes the comparison to other studies feasible. Main limitation is that the cohort of male survivors in a long-term observational study is obviously selected. The participants were surviving Caucasian men from the highest socioeconomic group, and their health and characteristics probably differ from those of the general 
population, for example, the prevalence of obesity was low in this cohort born in the years 1919-1934. The results cannot thus be directly applied to other populations. However, the homogeneous cohort is also a strength through reducing confounding, which may be important in a study related to lifestyle. The physical activity was self-reported, though we did not measure physical fitness, which is clearly a limitation of this study as two recent papers state the importance of measured physical fitness $(24,25)$. Although we adjusted for selfreported physical activity, it could be over- or underestimated by the participants. Moreover, our study sample was not very large, but the long follow-up time (32 years) combined with the robust results between the metabolic status and quality of life, enhance the significance of this study.

\section{Conclusions}

All-cause mortality during a very long follow-up (32 years) to old age was not affected by metabolically healthy overweight/obesity as compared to metabolically healthy normal weight in late midlife (mean 60 years) in our study. However, overweight-- even metabolically healthy -- tended to impair odds for successful aging.

\section{Funding}

This work was supported by Gustaf och Victoria Frimurarestiftelse; VTR-funding of the Helsinki University Hospital (TYH 2014245; 2015211); the Academy of Finland (grant number 311492). In addition, SKJ is supported by Päivikki ja Sakari Sohlberg foundation; MK is supported by NordForsk, the UK Medical Research Council (R024227) and Helsinki Institute of Life Sciences; VS is supported by the Finnish Foundation for Cardiovascular Research. The sponsors had no role in the design or conduct of the study; collection, 
282 management, analysis, and interpretation of the data; or preparation, review, or approval of 283 the manuscript.

284 Disclosures. SKJ, AU, AYS, MvB, MK, KL report no disclosures, VS has participated in a 285 conference trip sponsored by Novo Nordisk and received a modest honorarium from the same 286 source for participating in an advisory group meeting, TES reports various cooperation 287 (educational, research, consultation) with several companies marketing cholesterol-lowering 288 drugs including Amgen, AstraZeneca, Merck, OrionPharma, Pfizer, Servier. Minor stock in 289 OrionPharma.

290 


\section{REFERENCES}

1. Arnlov J, Ingelsson E, Sundstrom J, Lind L. Impact of body mass index and the metabolic syndrome on the risk of cardiovascular disease and death in middle-aged men. Circulation. 2010;121:230-236. DOI:

10.1161/CIRCULATIONAHA.109.887521.

2. Lavie CJ, Shutter De, Milani RV. Healthy obese versus unhealthy lean: the obesity paradox. Nat Rev Endocrinol 2015;11:55-62. DOI: 10.1038/nrendo.2014.165.

3. Velho S, Paccaud F, Waeber G, Vollenweider P, Marques-Vidal P. Metabolically healthy obesity: Different prevalencies using different criteria. Eur. J. Clin Nutr. 2010;64:1043-1051. DOI: 10.1038/ejcn.2010.114

4. Pajunen P, Kotronen A, Korpi-Hyövälti E, Keinänen-Kiukaanniemi S, Oksa H, Niskanen L, Saaristo T, Saltevo JT, Sundvall J, Vanhala M, Uusitupa M, Peltonen M.. Metabolically healthy and unhealthy obesity phenotypes in the general population: the FIN-D2D Survey. BMC Public Health. 2011;11:754. DOI: $10.1186 / 1471-2458-11-754$.

5. Mongraw-Chaffin M, Foster MC, Anderson CAM, Burke GL, Haq N, Kalyani RR, Ouyang P, Sibley CT, Tracy R, Woodward M, Vaidya D . Metabolically Healthy Obesity, Transition to Metabolic Syndrome, and Cardiovascular Risk. J Am Coll Cardiol 2018;17:1857-1865. DOI: 10.1016/j.jacc.2018.02.055.

6. Ortega FB, Lee DC, Katzmarzyk PT, Ruiz JR, Sui X, Church TS, Blair SN.. The intriguing metabolically healthy but obese phenotype: cardiovascular prognosis and role of fitness. Eur Heart J. 2013;34:389-97. DOI: 10.1093/eurheartj/ehs174.

7. Frisard MI1, Fabre JM, Russell RD, King CM, DeLany JP, Wood RH, Ravussin E; Louisiana Healthy Aging Study. Physical Activity Level and Physical 
Functionality in Nonagenarians Compared to Individuals Aged 60-74 Years. J Gerontol A Biol Sci Med Sci. 2007; 62:783-788.

8. Bell JA, Hamer M, Sabia S, Singh-Manoux A, Batty GD, Kivimäki M. The natural course of healthy obesity over 20 years. J Am Coll Cardiol 2015;65:201-2. DOI: 10.1016/j.jacc.2014.09.077.

9. Strandberg TE, Strandberg A, Salomaa VV, Pitkälä K, Miettinen TA. Impact of midlife weight change on mortality and quality of life in old age. Prospective cohort study. Int J Obes Relat Metab Disord. 2003;27:950-4.

10. Depp CA, Harmell AL, Jeste D. Strategies for Successful Aging: A Research Update. Curr Psychiatry Rep. 2014;16:476. DOI: 10.1007/s11920-014-0476-6.

11. Huohvanainen E, Strandberg AY, Stenholm S, Pitkälä KH, Tilvis RS, Strandberg TE. Association of self-rated health in midlife with mortality and old age frailty: a 26-year follow-up of initially healthy men. J Gerontol A Biol Sci Med Sci. 2016;71:923-8. DOI: 10.1093/gerona/glv311.

12. Strandberg TE, Salomaa V, Strandberg AY, Vanhanen H, Sarna S, Pitkälä K, Rantanen K, Savela S, Pienimäki T, Huohvanainen E, Stenholm S, Räikkönen K, Tilvis RS, Tienari PJ, Huttunen J. Cohort Profile: The Helsinki Businessmen Study (HBS). Int J Epidemiol. 2016;45:1074-1074h.

13. Salomaa V, Tuomilehto J, Kartovaara L, Marti B, Nissinen A, Korhonen HJ, Pietinen P, Vartiainen E.Trends in cardiovascular risk factors in treated and untreated hypertensive and normotensive Finnish subjects, 1982-1987. Rev Epidemiol Sante Publique. 1990;38:493-500.

14. Miettinen TA, Huttunen JK, Naukkarinen V, Strandberg T, Mattila S, Kumlin T, Sarna S.Multifactorial primary prevention of cardiovascular diseases in middleaged men. JAMA 1985;254:2097-2102. 
15. Strandberg A, Strandberg TE, Salomaa VV, Pitkälä K, Häppölä O, Miettinen TA.A follow-up study found that cardiovascular risk in middle age predicted mortality and quality of life in old age. J Clin Epidemiol. 2004;57:415-21.

16. Ortega FB, Lavie CJ, Blair SN. Obesity and Cardiovascular Disease. Circ Res 2016;118:1752-70. DOI: 10.1161/CIRCRESAHA.115.306883.

17. Hays RD, Morales LS. The RAND-36 measure of health-related quality of life. Ann Med. 2001;33: 350-357.

18. Aalto AM, Aro AR, Teperi J. RAND-36 as a measure of health-related quality of life. Reliability, construct validity and reference values in the Finnish general population. Helsinki, Finland: Stakes, Research Reports; No. 101, 1999,

19. Barry VW, Caputo JL, Kang M. The Joint Association of Fitness and Fatness on Cardiovascular Disease Mortality: A Meta-Analysis.Prog Cardiovasc Dis. 2018: S0033-062030131-2. DOI: 10.1016/j.pcad.2018.07.004.

20. Eckel N, Li Y, Kuxhaus O, Stefan N, Hu FB, Schulze MB. Transition from metabolic healthy to unhealthy phenotypes and association with cardiovascular 
23. Stenholm S, Head J, Aalto V, Kivimäki M, Kawachi I, Zins M, Goldberg M, Platts LG, Zaninotto P, Magnusson Hanson LL, Westerlund H, Vahtera JBody mass index as a predictor of healthy and disease-free life expectancy between ages 50 and 75: a multicohort study. Int J Obes (Lond). 2017;41:769-775. DOI: 10.1038/ijo.2017.29.

24. Deedwania P, Lavie CJ. Dangers and Long-Term Outcomes in Metabolically Healthy Obesity: The Impact of the Missing Fitness Component. J Am Coll Cardiol. 2018;71:1866-1868. DOI: 10.1016/j.jacc.2018.02.057.

25. Lavie CJ, Ortega FB, Kokkinos P. Impact of Physical Activity and Fitness in Metabolically Healthy Obesity. J Am Coll Cardiol. 2018 Feb 20;71:812-813. DOI: 10.1016/j.jacc.2017.10.106. 
377 LEGENDS TO THE FIGURES

378

379 Figure 1. Flow chart of the study

380

381 Figure 2. Cumulative total mortality during 32-year follow-up

382 Groups (defined in Table 1) are metabolically healthy normal weight (MHN, solid line),

383 metabolically healthy overweight (MHO, dots), and metabolically unhealthy overweight

384 (MUO, solid-dot line).

385 


\begin{tabular}{|c|c|}
\hline Metabolic status groups & \\
\hline Metabolically healthy normal weight (MHN) & $\mathrm{BMI}<25 \mathrm{~kg} / \mathrm{m}^{2}$, not MetS \\
\hline $\begin{array}{l}\text { Metabolically healthy overweight and obesity } \\
\text { (MHO) }\end{array}$ & $\mathrm{BMI} \geq 25 \mathrm{~kg} / \mathrm{m}^{2}$, not MetS \\
\hline Metabolically unhealthy normal weight (MUN) & $\mathrm{BMI}<25 \mathrm{~kg} / \mathrm{m}^{2}$ with MetS \\
\hline $\begin{array}{l}\text { Metabolically unhealthy overweight and obesity } \\
\text { (MUO) }\end{array}$ & $\mathrm{BMI} \geq 25 \mathrm{~kg} / \mathrm{m}^{2}$ with MetS \\
\hline $\begin{array}{l}\text { Harmonized International Diabetes Federation } \\
\text { components * }\end{array}$ & riteria for MetS: $\geq 3$ of the following \\
\hline Triglycerides $\geq 1.69 \mathrm{mmol} / \mathrm{L}(150 \mathrm{mg} / \mathrm{dL})$ & \\
\hline HDL cholesterol $<1.04 \mathrm{mmol} / \mathrm{L}(40 \mathrm{mg} / \mathrm{dL})$ & \\
\hline $\begin{array}{l}\text { Systolic blood pressure } \geq 130 \mathrm{~mm} \mathrm{Hg} \text {, or diastolic } \\
\text { blood pressure } \geq 85 \mathrm{~mm} \mathrm{Hg} \text {, or diagnosis of } \\
\text { hypertension }\end{array}$ & \\
\hline $\begin{array}{l}\text { Fasting glucose } \geq 5.55(100 \mathrm{mg} / \mathrm{dL}), \text { or diagnosis } \\
\text { of diabetes }\end{array}$ & \\
\hline
\end{tabular}

388 MetS=metabolic syndrome.

$389 *$ Reference \# 16 


\begin{tabular}{|c|c|c|c|c|c|}
\hline Variable in $1985 / 86$ & $\begin{array}{l}\text { MHN, } \\
\mathrm{n}=469\end{array}$ & $\begin{array}{l}\text { MHO, } \\
\mathrm{n}=538\end{array}$ & $\begin{array}{l}\text { MUN, } \\
n=26\end{array}$ & $\begin{array}{l}\text { MUO, } \\
\mathrm{n}=276\end{array}$ & $p$ Value \\
\hline $\begin{array}{l}\text { Age, yrs, median (interquartile } \\
\text { range) }\end{array}$ & $60(57-64)$ & $59(56-63)$ & $60(57-64)$ & $60(56-63)$ & 0.032 \\
\hline BMI at 25 years, $\mathrm{kg} / \mathrm{m}^{2}$ & $21.9(0.1)$ & $23.2(0.1)$ & $22.1(0.4)$ & $23.2(0.1)$ & $<0.001$ \\
\hline BMI, $\mathrm{kg} / \mathrm{m}^{2}$ & $23.2(0.09)$ & $27.1(0.08)$ & $23.8(0.4)$ & $29.0(0.1)$ & $<0.001$ \\
\hline Weight gain from 25 years, kg & $4.1(0.3)$ & $12.3(0.3)$ & $5.4(1.5)$ & $18.2(0.4)$ & $<0.001$ \\
\hline Waist circumference, $\mathrm{cm}$ & $89.6(0.3)$ & $98.4(0.3)$ & $92.7(1.3)$ & $105.7(0.4)$ & $<0.001$ \\
\hline Alcohol, g/week & $99.6(6.4)$ & $118.0(5.9)$ & $116.8(26.9)$ & $150.1(8.3)$ & $<0.001$ \\
\hline Smoking history, n (\%) & $245(52.2)$ & $324(60.2)$ & $19(73.1)$ & $196(71.0)$ & $<0.001$ \\
\hline $\begin{array}{l}\text { No regular exercise, } \\
\mathrm{n}(\%)\end{array}$ & $82(17.5)$ & $114(21.2)$ & $6(23.1)$ & $93(34.4)$ & $<0.001$ \\
\hline
\end{tabular}




\section{Table 2 Continued}

\begin{tabular}{llllll}
\hline Exercise hours among active, & $4(2-6)$ & $4(2-6)$ & $4(2-7)$ & $4(2-6)$ & 0.57 \\
median (IQ range) & & & & & $<0.001$ \\
Systolic BP, mm Hg & $136.0(0.8)$ & $139.8(0.7)$ & $147.0(3.2)$ & $145.7(1.0)$ & $<0.001$ \\
Diastolic BP, mm Hg & $84.8(0.4)$ & $88.4(0.4)$ & $90.2(1.8)$ & $91.1(0.6)$ & $<0.001$ \\
Fasting blood glucose & $4.68(0.05)$ & $4.73(0.05)$ & $5.62(0.22)$ & $5.65(0.07)$ & \\
Cholesterol, mmol/L & $6.4(0.1)$ & $6.4(0.05)$ & $6.3(0.2)$ & $6.6(0.1)$ & $<0.091$ \\
HDL cholesterol, mmol/L & $1.52(0.02)$ & $1.41(0.02)$ & $1.02(0.07)$ & $1.1680 .02)$ & 0.57 \\
LDL cholesterol, mmol/L & $4.4(0.05)$ & $4.5(0.05)$ & $4.4(0.2)$ & $4.4(0.07)$ & $<0.001$ \\
Triglycerides, mmol/L & $1.16(0.04)$ & $1.31(0.03)$ & $2.11(0.15)$ & $2.3880 .05)$ & \\
\hline
\end{tabular}

394 


\section{Table 2 Continued}

\begin{tabular}{llllll}
\hline Variable in 2000 & $\mathrm{n}=361$ & $\mathrm{n}=401$ & $\mathrm{n}=19$ & $\mathrm{n}=196$ & \\
\hline BMI, kg/m² & $23.4(0.1)$ & $26.7(0.1)$ & $23.4(0.6)$ & $27.9(0.2)$ & $<0.001$ \\
Alcohol, g/week & $103.4(7.3)$ & $126.0(7.0)$ & $89.6(31.4)$ & $136.3(10.1)$ & 0.025 \\
Present smokers, (\%) & $30(8.3)$ & $16(4.0)$ & $2(11.1)$ & $14(7.1)$ & 0.017 \\
$\begin{array}{l}\text { No regular exercise, } \\
\text { n (\%) }\end{array}$ & $48(13.3)$ & $74(18.5)$ & $2(10.5)$ & $46(23.5)$ & \\
$\begin{array}{l}\text { Exercise hours among active, } \\
\text { median (IQ range) }\end{array}$ & $5(3-8)$ & $5(3-9)$ & $4(2-6)$ & $5(3-8)$ & \\
\end{tabular}

\begin{tabular}{llllll}
\hline Variable in 2007 & $\mathrm{n}=245$ & $\mathrm{n}=247$ & $\mathrm{n}=12$ & $\mathrm{n}=127$ & \\
\hline BMI, kg/m² & $23.1(0.2)$ & $26.2(0.2)$ & $22.9(0.7)$ & $27.3(0.2)$ & $<0.001$ \\
Alcohol, g/week & $86.2(7.1)$ & $104.0(7.1)$ & $77.1 .(32.0)$ & $100.3(9.8)$ & 0.30 \\
$\begin{array}{l}\text { Present smokers, n (\%) } \\
\text { No regular exercise, }\end{array}$ & $9(3.7)$ & $8(3.3)$ & $1(8.3)$ & $3(2.4)$ & 0.71 \\
n (\%) & $34(13.9)$ & $45(18.2)$ & $2(16.7)$ & $25(19.7)$ & 0.37 \\
$\begin{array}{l}\text { Exercise hours among active, } \\
\text { median (IQ range) }\end{array}$ & $5(3-7)$ & $5(3-8)$ & $4(2-7)$ & $5(2-8)$ & 0.65 \\
& & & & \\
\end{tabular}

395 Values are means (SE) for continuous variables. 
Table 3. Health-Related Quality of Life in 2000 and 2007 adjusted for age, systolic

399 bloodpressure, log triglycerides and smoking at baseline in 1985/86

\begin{tabular}{lllll}
\hline $\begin{array}{l}\text { RAND-36 subscale } \\
\text { in } 2000\end{array}$ & $\begin{array}{l}\text { MHN, } \\
\mathrm{n}=361\end{array}$ & $\begin{array}{c}\text { MHO, } \\
\mathrm{n}=401\end{array}$ & $\begin{array}{l}\text { MUO, } \\
\mathrm{n}=196\end{array}$ & $p$ Value $\dagger$ \\
\hline Physical functioning & $81.6(1.2)$ & $76.3(1.1)^{* *}$ & $75.7(1.6)^{* *}$ & 0.003 \\
Role physical & $76.4(2.1)$ & $66.0(1.9)^{* *}$ & $62.1(2.7)^{* *}$ & 0.001 \\
Role emotional & $83.1(1.9)$ & $73.2(1.8)^{* *}$ & $73.1(2.6)^{* *}$ & $<0.001$ \\
Vitality & $70.2(1.2)$ & $68.4(1.1)$ & $67.0(1.5)$ & 0.32 \\
Mental health & $83.2(1.0)$ & $80.7(0.9)$ & $80.4(1.3)$ & 0.13 \\
Social functioning & $86.9(1.2)$ & $84.8(1.1)$ & $83.4(1.6)$ & 0.28 \\
Bodily pain & $81.6(1.2)$ & $76.3(1.2)^{* *}$ & $77.9(1.7)$ & 0.008 \\
General health & $62.1(1.0)$ & $58.2(1.0)^{* *}$ & $59.5(1.4)$ & \\
\hline
\end{tabular}

400

401 
Table 3 Continued

\begin{tabular}{lllll}
\hline $\begin{array}{l}\text { RAND-36 subscale } * \\
\text { in } 2007\end{array}$ & $\begin{array}{l}\text { MHN, } \\
\mathrm{n}=245\end{array}$ & $\begin{array}{c}\text { MHO, } \\
\mathrm{n}=247\end{array}$ & $\begin{array}{l}\text { MUO, } \\
\mathrm{n}=127\end{array}$ & $p$ Value $\dagger$ \\
\hline Physical functioning & $76.8(1.5)$ & $73.4(1.5)$ & $68.9(2.1)^{* *}$ & 0.037 \\
Role physical & $75.8(2.6)$ & $66.8(2.5)^{* *}$ & $55.5(3.5)^{* *}$ & 0.0005 \\
Role emotional & $83.6(2.3)$ & $77.7(2.3)$ & $66.4(3.2)^{* *}$ & 0.0015 \\
Vitality & $71.9(1.2)$ & $69.6(1.2)$ & $68.1(1.7)$ & 0.27 \\
Mental health & $82.6(1.0)$ & $80.1(1.0)$ & $80.4(1.4)$ & 0.21 \\
Social functioning & $86.4(1.2)$ & $83.1(1.2)$ & $81.0(1.6)^{* *}$ & 0.046 \\
Bodily pain & $81.7(1.4)$ & $79.3(1.4)$ & $74.1(2.0)^{* *}$ & 0.037 \\
General health & $61.7(1.1)$ & $59.5(1.6)$ & $56.2(1.6)^{* *}$ & 0.065 \\
\hline
\end{tabular}

403 Variables are mean (SE).

$404 *$ Score in subscales between 0 (worst) and 100 (best) points.

$405 \uparrow$ Analysis of covariance (ANCOVA).

$406 * *$ Significantly different from MHN (Bonferroni test for multiple comparisons). 
Table 4. Multivariate-Adjusted Hazard Ratios of Total Mortality and Odds Ratios of Reaching 90 Years of Age During the 32-Year Follow- up of the Helsinki Businessmen Study

HR $(95 \% \mathrm{CI})$ of total mortality during 32-year follow-up *

\begin{tabular}{lccr}
\hline & MHN & MHO & MUO \\
\hline Model A $\dagger$ & 1.0 & $1.17(1.01-1.36)$ & $1.53(1.29-1.82)$ \\
Model B + & 1.0 & $1.08(0.93-1.27)$ & $1.18(0.95-1.47)$ \\
\hline
\end{tabular}

OR $(95 \% \mathrm{CI})$ of reaching 90 years

of age $\S$

\begin{tabular}{llll}
\hline Model $\mathrm{A} \dagger$ & 1.0 & $0.78(0.57-1.06)$ & $0.59(0.39-0.87)$
\end{tabular}

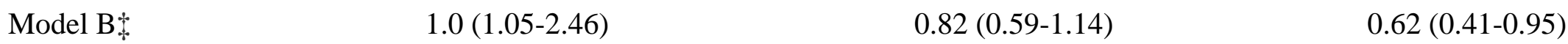

*HR was calculated using the Cox regression analysis with MHN as reference (HR = 1.0). $\uparrow$ Model A: adjusted for age at baseline in $1985 / 86$.

$\$$ Model B: adjusted for age, systolic blood pressure, log triglycerides, and smoking at baseline. § OR was calculated using logistic regression with $\mathrm{MHN}$ as reference $(\mathrm{OR}=1.0)$.

$\mathrm{HR}=$ hazard ratio; $\mathrm{OR}=$ odds ratio; $\mathrm{CI}=$ confidence interval 
Figure 1.
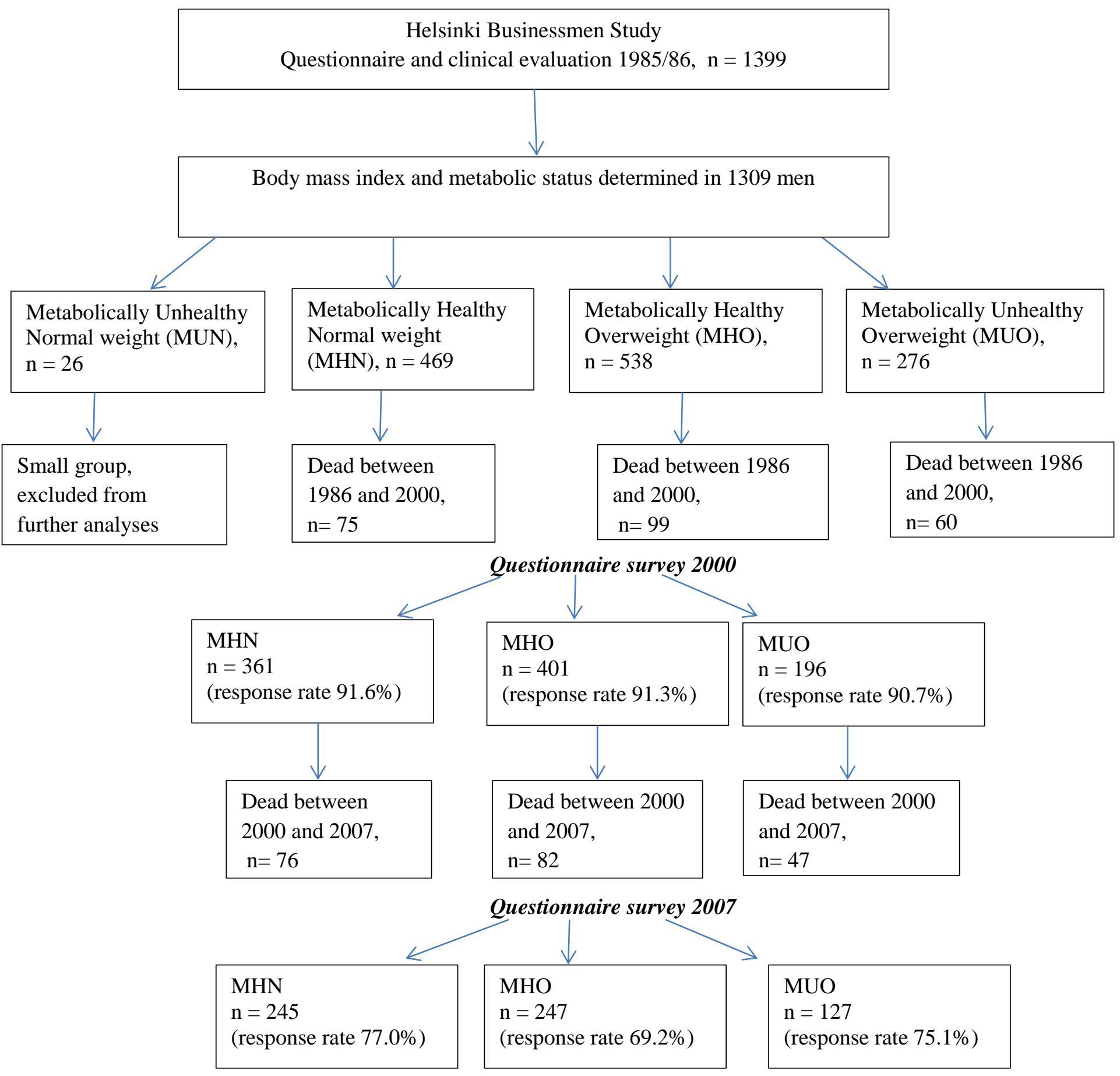
Figure 2

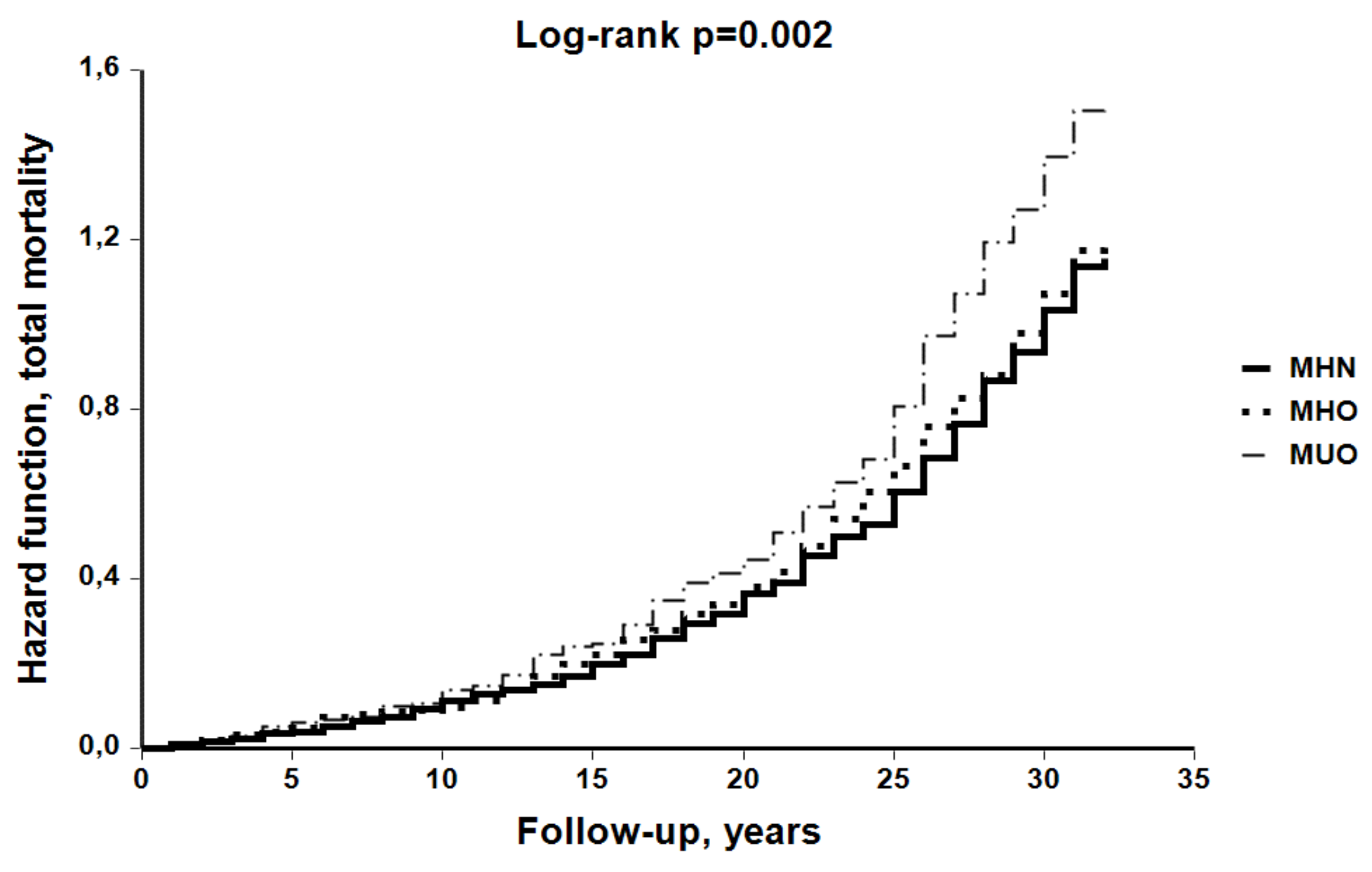

